\title{
Quinolyl functionalized spiro[fluorene-9,9'-xanthene] host materials with bipolar characteristics for green and red phosphorescent organic light-emitting diodes
}

Bao-Yi Ren ${ }^{\mathrm{a}, \mathrm{c}}$, Dao-Kun Zhong ${ }^{\mathrm{a}}$, Ya-Guang Sun ${ }^{\mathrm{a}}$, Xiang-Hua Zhao ${ }^{\mathrm{b}, *}$, Qi-Jian Zhang ${ }^{\mathrm{c}}$, Yi Liu ${ }^{\mathrm{c}, *}$, Matthew Jurow ${ }^{\mathrm{c}}$, Ming-Li Sun ${ }^{\mathrm{d}, *}$, Zhen-Song Zhang ${ }^{\mathrm{e}}$, Yi Zhao ${ }^{\mathrm{e}}$

${ }^{a}$ Key Laboratory of Inorganic Molecule-Based Chemistry of Liaoning Province, College of Applied Chemistry, Shenyang University of Chemical Technology, Shenyang 110142, China

${ }^{\mathrm{b}}$ College of Chemistry and Chemical Engineering, Xinyang Normal university, Xinyang 464000, China

c The Molecular Foundry, Lawrence Berkeley National Laboratory, One Cyclotron Road, Berkeley 94720, United States

${ }^{\mathrm{d}}$ Department of Chemistry, College of Science, Northeast Forestry University, Harbin 150040, China

e State Key Laboratory on Integrated Optoelectronics, College of Electronics Science and Engineering, Jilin University, Changchun 130012, China

*Corresponding authors. Tel.: + 1510486 6287; Fax: +1 5104867413 (Y. Liu)

E-mail addresses: 4773zxh@163.com (X.-H. Zhao), yliu@lbl.gov (Y. Liu), sml98@163.com (M.-L. Sun)

\section{Graphical abstract}
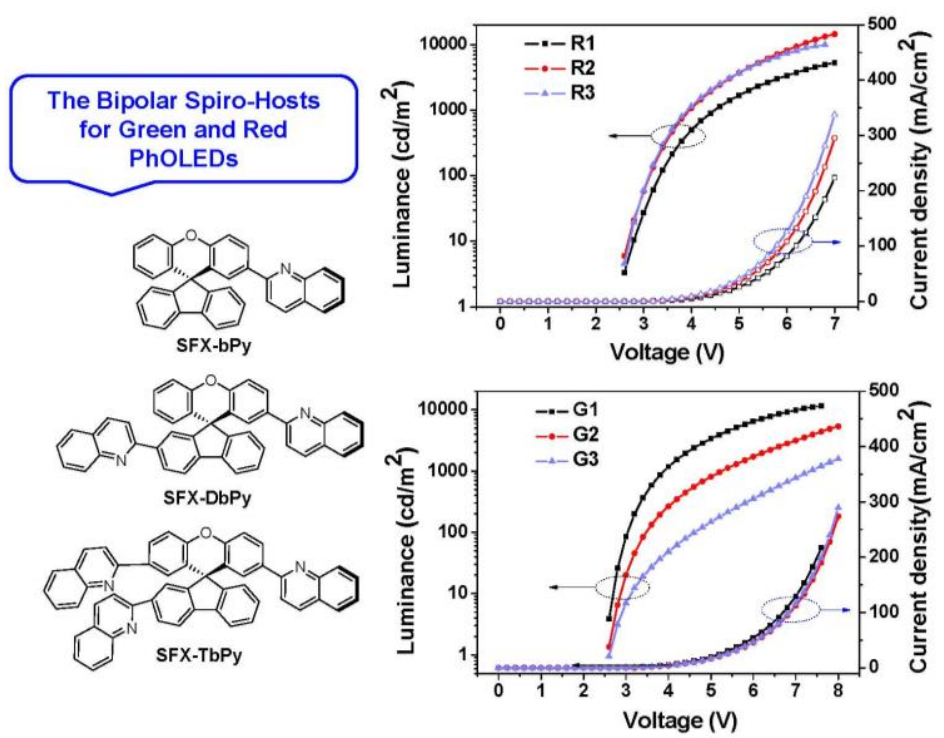

\section{ABSTRACT}

Spiro[fluorene-9,9'-xanthene] (SFX) bipolar hosts bearing one, two and three quinolyl substituents, namely SFX-bPy, SFX-DbPy and SFX-TbPy, were designed and synthesized for phosphorescent organic light emitting diodes (PhOLEDs). The successive substitution of quinoline at 2', 2 and 7' positions of SFX results in reduced LUMO energy levels while leaving the HOMO energy levels nearly intact. The impact of quinoline substitution in these SFX-based hosts on PhOLED performance was investigated in detail through green and red model devices. For the green emitting devices, the device based on SFX-bPy host showed better performance ( $23.6 \mathrm{~cd} \mathrm{~A}^{-1}, 23.4$ $\left.\operatorname{lm~} \mathrm{W}^{-1}, 6.3 \%\right)$ due to high triplet energy level $\left(T_{1}\right)$ and balanced carriers-transporting ability. In contrast, for the red PhOLED devices, the device hosted by SFX-DbPy displayed higher performance (15.8 $\mathrm{cd} \mathrm{A}^{-1}, 16.0 \mathrm{~lm} \mathrm{~W} \mathrm{~m}^{-1}, 9.1 \%$ ), attributable to the well matched $T_{1}$ and separated frontier molecular orbitals. This work thus sheds light on the rational design of SFX-based bipolar 
hosts for more efficient PhOLEDs.

Keywords: PhOLEDs; host materials; spiro[fluorene-9,9'-xanthene]; quinoline; substitution effect

\section{Introduction}

Phosphorescent organic light-emitting diodes (PhOLEDs) have attracted immense interests since they can, in theory, approach a $100 \%$ internal quantum efficiency by harvesting both singlet and triplet excitons simultaneously and show great potential in flat-panel display and solid-state lighting [1-3]. To avoid the self-aggregation quenching and triplet-triplet annihilation (TTA) in solid state, phosphorescent emitters are usually doped into an appropriate host as the emitting layer (EML) [4,5]. An ideal host material for PhOLEDs is expected to meet the following intrinsic requirements: i) a triplet energy level $\left(T_{1}\right)$ higher than that of the phosphorescent dopant to maintain effective exothermic energy transfer from host to guest; ii) good carriers injecting/transporting properties to balance the charge flux and reduce the driving voltage; iii) thermal and morphological stability to obtain the long lifetime and stable CIE (Commission Internationale de I'Eclairage) chromaticity coordinates of corresponding devices. Large conjugated length is generally undesirable for host material to achieve high $T_{1}$, therefore small footprint molecules with considerable carriers injecting/transporting ability and high $T_{1}$, such as carbazole [6], triphenylamine [7], fluorene [8-10], are utilized as the chromophores to construct hosts. Furthermore, a host with bipolar feature is highly desired to achieve high and balanced charge transporting ability, which is helpful to simplify the device structure and reduce the cost of PhOLEDs, such as single-layer device [11]. One straightforward strategy to achieve bipolar transport in organic molecules is to incorporate both electron-donating and electron-withdrawing groups, the so-called donor-acceptor (D-A) structure, into a single molecule [12,13]. Another way to construct bipolar hosts is to use a building block that possesses the characteristics of dual channel for transporting both electron and hole, such as spiro aromatics. Chart 1 lists some representative spiro molecules that are employed as host materials for PhOLEDs [14-20]. Among these, spirobifluorene (SBF) is a classical spiro building unit for organic electronics with three-dimensional orthogonal configuration and two independent $\pi$-systems interrupted by intramolecular $s p^{3}$ carbon atom at the 9-position of fluorene, which can confer good thermal and morphological stability, as well as binary channels injecting/transporting ability for carriers. Hence, SBF is a versatile structural unit to build high performance host materials for PhOLEDs [21-26]. Nevertheless, the synthetic procedure of SBF is complicated, and the electronic properties of SBF is relative monotonous because of the same fluorene unit at the flanks of $s p^{3}$ carbon atom.

Compared with SBF, spiro[fluorene-9,9'-xanthene] (SFX) has the following features: i) it can be synthesized by a facile "one-pot" route, thus is very cost-effective; ii) it contains orthogonally arranged fluorene and xanthene moieties, which incurs independent electronic properties with separated frontier molecular orbitals (FMOs) and bipolar characteristics; iii) there are multiple positions on the aromatic units for functionalization [27,28]. Therefore, SFX has emerged as versatile molecular backbone for use in the field of organic electronics [29-32]. In the area of OLEDs, SFX-based materials have been employed as deep-blue and green fluorescent emitter [33-36], as universal hosts for phosphorescent and thermally activated delayed fluorescence (TADF) OLEDs [37-43], as ligands for $\mathrm{Pt}^{\mathrm{II}}$ and $\mathrm{Eu}^{\mathrm{III}}$-based emitter [44,45], and as the hole-transporting materials [46]. In our previous works, a series of SFX-based host materials had 
been synthesized and investigated for PhOLEDs. Electron-withdrawing groups (e.g. phosphine oxide (PO)) [37-39], electron-donating groups (e.g. methyl/methoxy-arylfluoene) [40] and electroneutral unit (e.g. phenylfluorene) [41] had been introduced into SFX by insulating linkage, and the PhOLEDs devices based on these hosts display low driving voltages and high efficiencies. For instance, the dimeric SFX is a efficient host materials, and the corresponding red, green and blue PhOLEDs devices all possess low turn-on voltages between 2.4 3.1 V [42]. Besides, it was found that a compromise is also required between the $T_{1}$ and HOMO/LUMO levels of the hosts for enhancing the carriers injecting/transporting ability and the device performance [37]. We have discovered that fine tuning frontier molecular orbital energy levels without affecting the high $T_{1}$ could be realized by introducing insulating linker-bridged arylfluorene on SFX [40]. All of the research results indicate that the SFX is a promising building block to construct bipolar hosts for PhOLEDs.

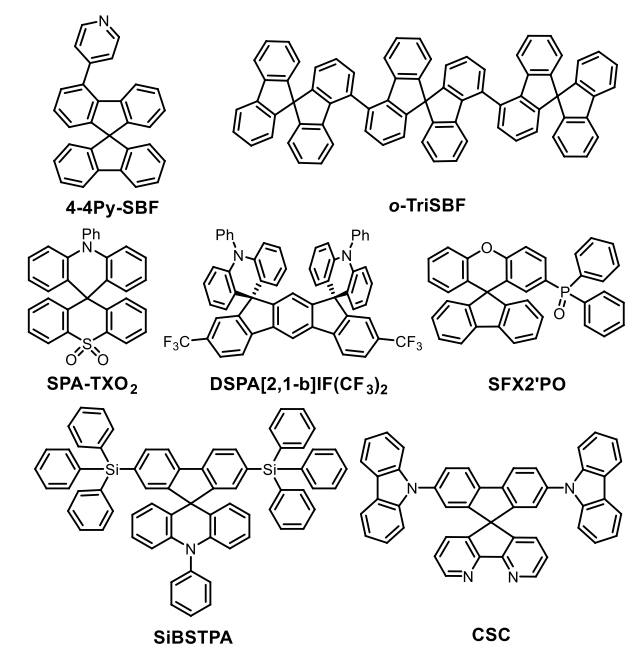

Chart 1. Some examples of spiro compounds as host materials for PhOLEDs.

In this contribution, a series of quinolyl-substituted SFX hosts (Scheme 1) were designed and synthesized. Quinoline unit was utilized considering the wide use of its analogues in organic optoelectronic devices because of the high electron transporting ability and thermal stability [47-49]. In order to improve/balance carrier injection/transport, quinoline was also introduced as electron transporting (ET) unit into SFX via conjugated linkage. The influence of substitution position and number of quinolyl groups on the electrochemical and optophysical properties of SFX was explored in detail. The relationship between the structure and performance of these hosts for PhOLEDs was evaluated by testing the green and red model devices.

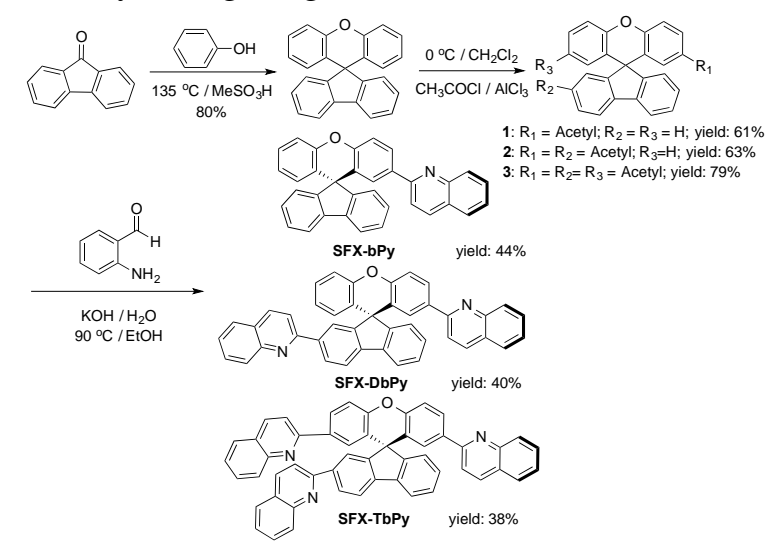

Scheme 1. Synthetic routes of SFX-bPy, SFX-DbPy and SFX-TbPy. 


\section{Experimental section}

\subsection{Synthesis of 2-(spiro[fluorene-9,9'-xanthen]-2'-yl)quinoline (SFX-bPy)}

SFX was synthesized according to our previously published method [27]. Under $\mathrm{N}_{2}$ protection, $\mathrm{AlCl}_{3}(3.0 \mathrm{~g} 22.5 \mathrm{mmol})$, and SFX (3.32 g, $\left.10 \mathrm{mmol}\right)$ were mixed in $50 \mathrm{~mL}$ anhydrous $\mathrm{CH}_{2} \mathrm{Cl}_{2}$. $\mathrm{CH}_{3} \mathrm{COCl}(0.71 \mathrm{~mL}, 10 \mathrm{mmol})$ was dissolved in $30 \mathrm{~mL}$ anhydrous $\mathrm{CH}_{2} \mathrm{Cl}_{2}$ and added dropwise into the above mixture, stirred for $30 \mathrm{~min}$, and then reacted over a period of $2 \mathrm{~h}$ at room temperature. The resulting mixture was washed with $12 \% \mathrm{HCl}$ and extracted with $\mathrm{CH}_{2} \mathrm{Cl}_{2}$. The combined organic layers were then subjected to silica-gel column chromatography to afford $2.23 \mathrm{~g}$ white powder $\mathbf{1}$ in $61 \%$ yield. Following the similar procedure, compounds $\mathbf{2}$ and $\mathbf{3}$ can be obtained by changing the ratio of reactants.

Under $\mathrm{N}_{2}$ protection, $1(1.12 \mathrm{~g}, 3.0 \mathrm{mmol}), o$-aminobenzaldehyde $(0.40 \mathrm{~g}, 3.3 \mathrm{mmol})$ and saturated aqueous solution of $\mathrm{K}_{2} \mathrm{CO}_{3}(5 \mathrm{~mL})$ were mixed in $25 \mathrm{~mL}$ ethanol, and the mixture was reacted at $90{ }^{\circ} \mathrm{C}$ for $24 \mathrm{~h}$. The resulting mixture was washed by water and extracted with $\mathrm{CH}_{2} \mathrm{Cl}_{2}$. The combined organic layers were subjected to silica-gel column chromatography to afford $0.61 \mathrm{~g}$ white solid in $44 \%$ yield. ${ }^{1} \mathrm{H}$ NMR (400 MHz, $\left.\mathrm{CDCl}_{3}, \mathrm{ppm}\right): \delta 8.13(\mathrm{dd}, J=8.6,1 \mathrm{H}), 8.0(\mathrm{~m}, 2 \mathrm{H})$, $7.84(\mathrm{~d}, J=7.63,2 \mathrm{H}), 7.71(\mathrm{~d}, J=8.04,1 \mathrm{H}), 7.64(\mathrm{t}, J=6.98,1 \mathrm{H}), 7.41(\mathrm{~m}, 5 \mathrm{H}), 7.28(\mathrm{~s}, 1 \mathrm{H})$, $7.22(\mathrm{~m}, 5 \mathrm{H}), 7.08(\mathrm{~s}, J=2.16,1 \mathrm{H}), 6.80(\mathrm{~s}, J=8.12,1 \mathrm{H}), 6.44(\mathrm{~s}, J=7.81,1 \mathrm{H}) .{ }^{13} \mathrm{C}$ NMR $(101$ $\left.\mathrm{MHz}_{\mathrm{CDCl}}\right) \delta 156.48,154.86,152.58,151.24,148.06,139.73,136.43,135.01,129.54,128.48$, $128.16,127.94,127.29,127.15,126.83,125.99,125.78,125.10,123.53,120.06,118.68,117.51$, 116.82, 77.33, 77.01, 76.69, 54.41. IR (KBr): $v=3064,2372,2314,1596,1568,1478,1455,1427$, 1281, 1241, 1123, $1095 \mathrm{~cm}^{-1}$. GC-MS (EI) m/z 459 [M] . Anal.calcd for $\mathrm{C}_{34} \mathrm{H}_{21} \mathrm{NO}: \mathrm{C}, 88.86 ; \mathrm{H}$, $4.61 ; \mathrm{N}, 3.05$; found: $\mathrm{C}, 88.83 ; \mathrm{H}, 4.65 ; \mathrm{N}, 3.02$.

\subsection{Synthesis of 2,2'-(spiro[fluorene-9,9'-xanthene]-2,2'-diyl)diquinoline (SFX-DbPy)}

The procedures were similar to SFX-DbPy. $2(1.3 \mathrm{~g}, 3.1 \mathrm{mmol})$ and $o$-aminobenzaldehyde $(0.79 \mathrm{~g}, 6.5 \mathrm{mmol})$ were used, and the product was obtained as a white solid $(0.74 \mathrm{~g}, 40 \%$ yield $)$. ${ }^{1} \mathrm{H}$ NMR $\left(400 \mathrm{MHz}, \mathrm{CDCl}_{3}\right): \delta(\mathrm{ppm}) 8.37(\mathrm{~d}, J=7.99,1 \mathrm{H}), 8.16(\mathrm{~m}, 1 \mathrm{H}), 8.11(\mathrm{~m}, 2 \mathrm{H}), 7.99$ $(\mathrm{m}, 4 \mathrm{H}), 7.90(\mathrm{~d}, J=7.62,1 \mathrm{H}), 7.76(\mathrm{~d}, J=8.64,2 \mathrm{H}), 7.68(\mathrm{~m}, 2 \mathrm{H}), 7.62(\mathrm{~m}, 1 \mathrm{H}), 7.43(\mathrm{~m}, 5 \mathrm{H})$, $7.30(\mathrm{~s}, J=9.35,1 \mathrm{H}), 7.25(\mathrm{~m}, 2 \mathrm{H}), 7.21(\mathrm{~m}, 1 \mathrm{H}), 7.68(\mathrm{~m}, 1 \mathrm{H}), 7.14(\mathrm{~d}, J=2.16,1 \mathrm{H}), 6.50(\mathrm{t}$, $J=7.85,1 \mathrm{H}) .{ }^{13} \mathrm{C} \mathrm{NMR}\left(101 \mathrm{MHz}, \mathrm{CDCl}_{3}\right) \delta 156.92,156.45,156.03,155.41,152.56,151.21$, $148.14,147.99,141.41,139.98,138.81,136.68,136.54,135.13,129.66,129.61,129.51,129.48$, $128.93,128.32,128.17,128.07,127.98,127.40,127.39,127.32$, 127.14, 126.85, 126.25, 126.02, $125.82,124.95,124.73,124.69,123.69,120.62,120.51,119.15,118.80,117.69,116.95$. IR (KBr): $v=3059,2366,2310,1596,1483,1444,13201270,1100 \mathrm{~cm}^{-1}$. GC-MS (EI) m/z $586[\mathrm{M}]^{+}$. Anal.calcd for $\mathrm{C}_{43} \mathrm{H}_{26} \mathrm{~N}_{2} \mathrm{O}: \mathrm{C}, 88.03 ; \mathrm{H}, 4.47 ; \mathrm{N}, 4.77$; found: C, 88.06; H, 4.44; N, 4.74 .

\subsection{Synthesis of 2,2',2"-(spiro[fluorene-9,9'-xanthene]-2,2',7'-triyl)triquinoline (SFX-TbPy)}

The procedures were similar to SFX-TbPy. $3(1.4 \mathrm{~g}, 3.0 \mathrm{mmol})$ and $o$-aminobenzaldehyde $(1.2$ $\mathrm{g}, 10 \mathrm{mmol})$ were used, and the product was obtained as a white solid $(0.83 \mathrm{~g}, 38 \%$ yield $) .{ }^{1} \mathrm{H}$ NMR (400 MHz, CDCl $): \delta(\mathrm{ppm}) 8.41(\mathrm{~d}, J=9.46,1 \mathrm{H}), 8.18(\mathrm{~d}, J=8.55,2 \mathrm{H}), 8.08(\mathrm{dd}, J=8.28$, 3H), $7.99(\mathrm{~m}, 5 \mathrm{H}), 7.94(\mathrm{~d}, J=7.73,1 \mathrm{H}), 7.76(\mathrm{t}, J=9.22,2 \mathrm{H}), 7.70(\mathrm{~d}, J=7.66,2 \mathrm{H}), 7.64(\mathrm{~m}$, $3 \mathrm{H}), 7.43(\mathrm{~m}, 8 \mathrm{H}), 7.30(\mathrm{~s}, 2 \mathrm{H}), 7.15(\mathrm{~m}, 2 \mathrm{H}) .{ }^{13} \mathrm{C} \mathrm{NMR}\left(101 \mathrm{MHz}, \mathrm{CDCl}_{3}\right) \delta 156.39,155.85$, $152.32,148.05,141.43,136.63,136.49,135.42,129.63,129.58,129.55,129.46,128.08,127.29$, 
$127.14,126.86,126.01,125.87,124.79,118.75,117.72,29.70 . \mathrm{IR}(\mathrm{KBr}): v=3059,2378,2310$, 1596, 1550, 1483, 1427, 1325, 1275, $1100 \mathrm{~cm}^{-1}$. GC-MS (EI) m/z $713[\mathrm{M}]^{+}$. Anal. calcd for $\mathrm{C}_{52} \mathrm{H}_{31} \mathrm{~N}_{3} \mathrm{O}: \mathrm{C}, 87.49 ; \mathrm{H}, 4.38 ; \mathrm{N}, 5.89$; found: $\mathrm{C}, 87.46 ; \mathrm{H}, 4.35 ; \mathrm{N}, 5.86$.

\subsection{Instrumental methods}

The NMR spectrum was recorded on a Bruker AV400 MHz NMR spectrometer. Mass-spectra were collected using a GC-MS HP5988A system. UV-Vis absorption and photoluminescence spectra were recorded with a Shimadzu UV-3600 and a Shimadzu RF-5301PC spectrophotometer, respectively. Elenental analyses were measured on an E-2400 analyzer (Perkin-Elener).

\subsection{Theoretical computation methods}

Geometrical optimization for the ground and excited states was carried out at the B3LYP/6-31G and CIS/6-31G level, respectively. The TDDFT/B3LYP/6-31G calculations of the excitation energies were then performed at the optimized geometries. All the quantum-chemical calculations were performed using the Gaussian09 suite of programs [50].

\section{Results and discussion}

\subsection{Synthesis and photophysical properties}

The synthetic routes of SFX-bPy, SFX-DbPy and SFX-TbPy are depicted in Scheme 1. The target compounds were prepared by a three-step procedure. Initially, the spiro-structured SFX was facilely prepared by the one-pot reaction from 9-fluorenone and phenol under excessive $\mathrm{MeSO}_{3} \mathrm{H}$ conditions. Then, acetyl was sequentially introduced to 2', 2 and 7'-position of SFX by classical Friedel-Crafts reaction. Finally, the corresponding host bearing quinolyl was synthesized using acetyl-SFX and 2-aminobenzaldehyde under Friedländer condensation conditions. Different from common synthetic methods of organic semiconductor materials [51,52] with cost and toxic precious metal catalysts, palladium, ruthenium or rhodium etc, have not been used in these procedures. Quinoline units were introduced into the xanthene and fluorene moieties to not only balance carriers injecting/transporting but also tune appropriate triplet energy level of these hosts. All of these compounds were well soluble in common solvents such as chloroform, acetone and dichloromethane, and exhibited good thermal stabilities by thermogravimetric analysis (TGA). The decomposition temperature $T_{\mathrm{d}}$ of SFX-bPy, SFX-DbPy and SFX-TbPy are measured to be around $295{ }^{\circ} \mathrm{C}, 230^{\circ} \mathrm{C}$ and $160{ }^{\circ} \mathrm{C}$ (see the TGA curve in Fig. S1), respectively. Differential scanning calorimetric (DSC) studies indicated that both SFX-bPy and SFX-DbPy show good morphological stability with no crystallization, while SFX-TbPy has a distinct glass transition at $97{ }^{\circ} \mathrm{C}\left(T_{\mathrm{g}}\right.$, see the DSC curve in Fig. S1). However, it should be noted that SFX-TbPy yet presents a higher $T_{\mathrm{g}}$ than those of classical host materials for PhOLEDs such as $\mathrm{CBP}\left(62^{\circ} \mathrm{C}\right)$ or $m \mathrm{Cp}\left(55^{\circ} \mathrm{C}\right)$ [53].

The UV-vis and PL spectra of the three compounds are measured in dilute $\mathrm{CH}_{2} \mathrm{Cl}_{2}$, as shown in Fig. 1. SFX-bPy shows three absorption peaks at 331, 308 and $275 \mathrm{~nm}$, which can be attributed to $n \rightarrow \pi^{*}$ transition from xanthene moiety to fluorene moiety, the combination of $n \rightarrow \pi^{*}$ transition of xanthene moiety and $\pi \rightarrow \pi^{*}$ transition of fluorene moiety, as well as $\pi \rightarrow \pi^{*}$ transition of xanthene moiety according to the previous research [24], respectively. For SFX-DbPy and SFX-TbPy, the absorption peak around $308 \mathrm{~nm}$ was bathochromically shifted (for SFX-DbPy) and overlapped with the band centered at $331 \mathrm{~nm}$ (for SFX-TbPy), while the intensity of peak at $275 \mathrm{~nm}$ decreased. 
This was originated from the depression of $\pi^{*}$ orbital of their fluorene moieties and the decrease of non-bonding electron density of xanthene moieties because of the further quinoline substitutions located at 2 and 7' positions of SFX. The PL spectra of SFX-bPy, SFX-DbPy and SFX-TbPy are similar in solution state. For SFX-bPy, the emission peak is at $368 \mathrm{~nm}$; while the emission peak of SFX-DbPy and SFX-TbPy are both around $376 \mathrm{~nm}$, which was bathochromic shifted by about 8 $\mathrm{nm}(0.099 \mathrm{eV})$. This implies the small influence of further quinolyl substitution on the singlet excited state properties because of the fact that xanthene ring and fluorene ring are not conjugated and thus electronically separated. The $T_{1}$ of SFX-bPy, SFX-DbPy and SFX-TbPy were estimated to be $2.55 \mathrm{eV}, 2.44 \mathrm{eV}$ and $2.43 \mathrm{eV}$ from the highest energy $0-0$ phosphorescent emission (see Table 1 and Fig. S2), which are sufficiently high to confine the commonly used green and red phosphorescent emitters such as $\operatorname{Ir}(\mathrm{ppy})_{3}(2.4 \mathrm{eV})$ and $\operatorname{Ir}(\mathrm{MDQ})_{2} \mathrm{acac}(2.2 \mathrm{eV})$.

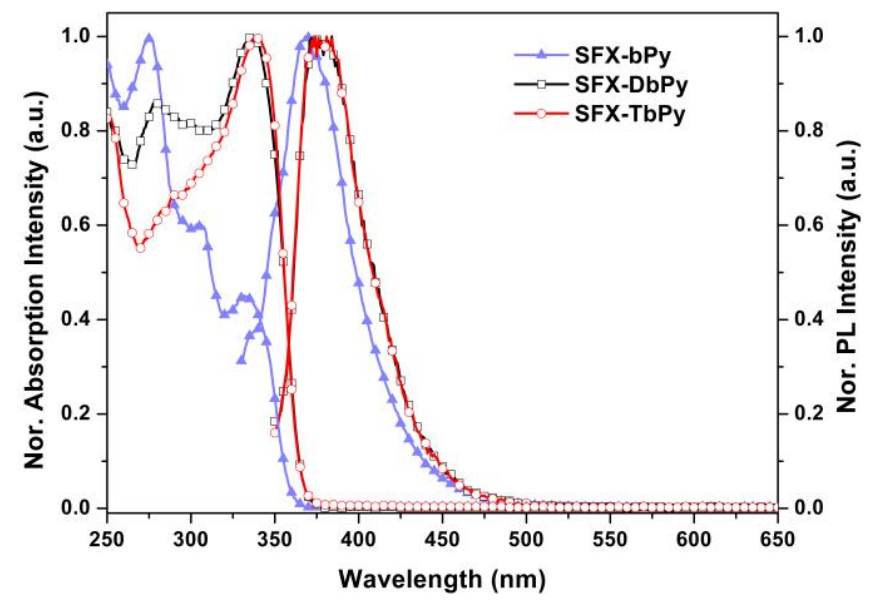

Fig. 1. Normalized absorption and fluorescence spectra of the hosts in dichloromethane

\subsection{Energy levels of the three hosts}

The frontier molecular orbitals (FMO) levels of the host materials were investigated by cyclic voltammetry (CV) (see Fig. S3) and the density functional theory (DFT) calculations (Table 2). The HOMO and LUMO levels of SFX-bPy, SFX-DbPy and SFX-TbPy obtained from electrochemical measurements are $-6.07 /-2.50,-6.09 /-2.62$ and $-6.07 /-2.71 \mathrm{eV}$, respectively. These results suggest that the number and location of the quinolyl substituent have little impact on the electron-donating ability of the host molecule. Accordingly, these hosts retain the similar HOMO levels $(-6.07 \sim-6.09 \mathrm{eV})$ in comparison to SFX $(-6.11 \mathrm{eV})$ [42], indicating that these hosts possess nearly the same hole-injecting/transporting ability. However, the LUMO energy levels of these hosts are lowered gradually and markedly by successively introducing quinolyl groups on 2', 2 and 7 ' positions of SFX, leading to enhanced electron-injecting/transporting ability. This tendency on the variation of HOMO and LUMO levels is in accordance with DFT simulation. For SFX-bPy, the HOMO is mainly attributed to xanthene and quinoline moieties, while the LUMO is mainly localized on the quinoline moiety. For SFX-DbPy and SFX-TbPy, almost complete charge separation between HOMO and LUMO is observed, and the HOMO is located at xanthene side while the LUMO is located at fluorene side, which is helpful for efficient hole- and electron-transporting and inhibiting back electron transfer. Additionally, the separation of FMOs implies that the hosts have bipolar transmission characteristics. 
Table 1. Physical parameters of quinolyl-substituted SFX compounds

\begin{tabular}{llllllll}
\hline Compound & $\begin{array}{l}T_{\mathrm{g}} \\
\left({ }^{\circ} \mathrm{C}\right)\end{array}$ & $\begin{array}{l}T_{\mathrm{d}} \\
\left({ }^{\circ} \mathrm{C}\right)\end{array}$ & $\begin{array}{l}\lambda_{\mathrm{abs}^{[\mathrm{b}]}} \\
(\mathrm{nm})\end{array}$ & $\begin{array}{l}\lambda_{\mathrm{em}} \\
(\mathrm{nm})\end{array}$ & $\begin{array}{l}\text { HOMO/LUMO } \\
(\mathrm{eV})\end{array}$ & $\begin{array}{l}E_{\mathrm{g}} \\
(\mathrm{eV})\end{array}$ & $\begin{array}{l}T_{1} \\
(\mathrm{eV})\end{array}$ \\
\hline SFX-bPy & - & 295 & $275(3.32), 308^{c}(3.21), 331(3.05)$ & 368 & $-6.07 /-2.50$ & 3.57 & 2.54 \\
SFX-DbPy & - & 230 & $279(3.30), 336(3.41)$ & $\sim 376$ & $-6.09 /-2.62$ & 3.47 & 2.44 \\
SFX-TbPy & 90 & 160 & $289(3.46), 341(3.54)$ & -376 & $-6.07 /-2.71$ & 3.36 & 2.43 \\
$\mathrm{SFX}^{a}$ & 154 & 380 & 361 & 398,417 & $-6.11 /-1.88$ & 4.23 & 2.88 \\
\hline
\end{tabular}

${ }^{a}$ from reference [42]. ${ }^{b} \mathrm{In} \mathrm{CH}_{2} \mathrm{Cl}_{2}\left(1 \times 10^{-5} \mathrm{M}\right)$. Extinction coefficients are reported in the logarithmic scale in the brackets. ${ }^{c}$ Shoulder peak.

Table 2. DFT calculated HOMOs and LUMOs of the hosts and SFX

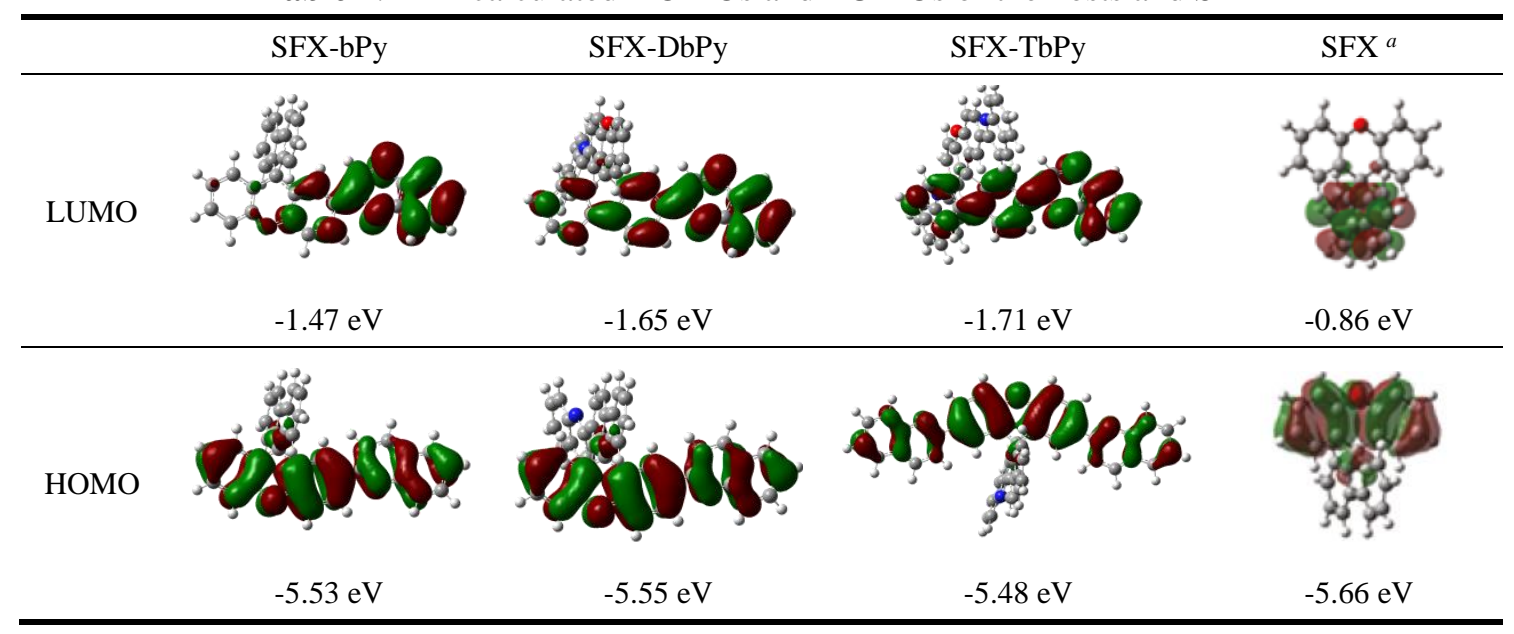

${ }^{a}$ from reference [37] and [42].

\subsection{Electroluminescent performance of PhOLEDs}

To better understand the bipolar characteristics of the three hosts, the hole-only and electron-only devices were fabricated with the following structures: ITO/MoO $x(2$ $\mathrm{nm}) / m$-MTDATA:MoO ${ }_{x}(30 \mathrm{~nm}, 15 \mathrm{wt} \%) / m$-MTDATA $(10 \mathrm{~nm}) / \mathrm{Ir}(\mathrm{ppz})_{3}(10 \mathrm{~nm}) / \mathrm{host}$ (30 $\mathrm{nm}) / \mathrm{Ir}(\mathrm{ppz})_{3}(10 \mathrm{~nm}) / m$-MTDATA $(10 \mathrm{~nm}) / \mathrm{m}-\mathrm{MTDATA}_{\mathrm{MoO}}(30 \mathrm{~nm}, 15 \mathrm{wt} \%) / \mathrm{MoO}_{x}(2 \mathrm{~nm}) / \mathrm{Al}$ $(100 \mathrm{~nm})$ (hole only), and $\mathrm{Al}(60 \mathrm{~nm}) / \mathrm{LiF}(1 \mathrm{~nm}) / \mathrm{Bphen}(40 \mathrm{~nm}) / \mathrm{host}(30 \mathrm{~nm}) / \mathrm{Bphen}(40 \mathrm{~nm}) / \mathrm{LiF}$ $(1 \mathrm{~nm}) / \mathrm{Al}(100 \mathrm{~nm})$ (electron only) (Fig.2). All of the hosts show bipolar characteristics with the SFX-bPy possessing the most balanced carriers injecting/transporting capability. The SFX-bPy demonstrates the best injection and transport properties of the three hosts, resulting in better charge carrier balance. However, the bipolar transport properties are not enhanced by the substitutions of quinoline at the 2 position (SFX-DbPY) and both the 2 and 7' positions (SFX-TbPy). 

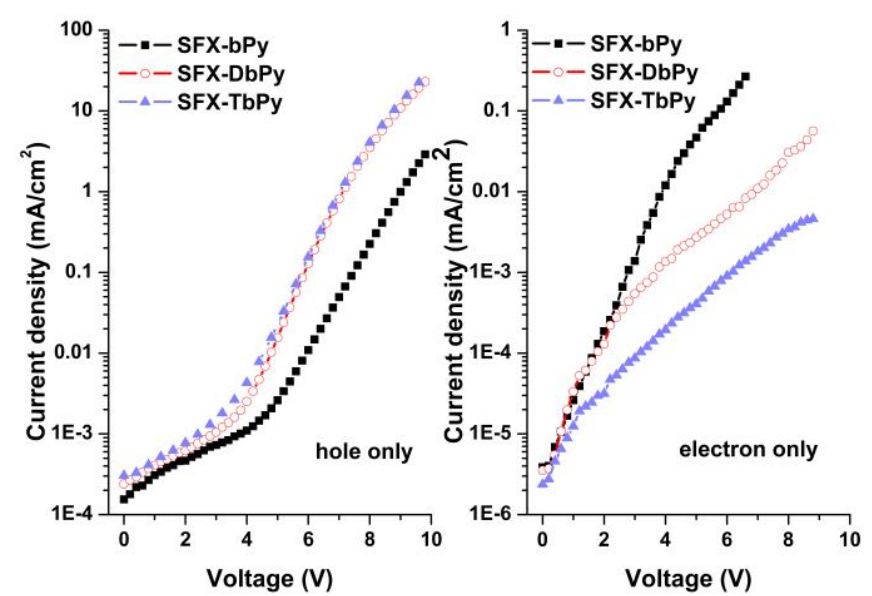

Fig. 2. $J-V$ curves of hole-only and electron-only devices.

Subsequently, to investigate the electroluminescent (EL) properties of SFX-bPy, SFX-DbPy and SFX-TbPy, a series of green and red PhOLEDs were fabricated with the configurations of ITO/MoO ${ }_{x}(2 \mathrm{~nm}) / m-\mathrm{MTDATA}_{\mathrm{MoO}_{x}}(15 \mathrm{wt} \%)(30 \mathrm{~nm}) / m$-MTDATA $(10 \mathrm{~nm}) / \mathrm{Ir}(\mathrm{ppz})_{3} \quad(10$ $\mathrm{nm}) /$ host $: \operatorname{Ir}(\mathrm{ppy})_{3}(6 \mathrm{wt} \%)(10 \mathrm{~nm}) / \mathrm{Bphen}(40 \mathrm{~nm}) / \mathrm{LiF}(1 \mathrm{~nm}) / \mathrm{Al}(100 \mathrm{~nm})$ (green-PhOLEDs) and ITO/MoO ${ }_{x}(2 \mathrm{~nm}) / m$-MTDATA : $\mathrm{MoO}_{x}(15 \mathrm{wt} \%)(30 \mathrm{~nm}) / m$-MTDATA $(10 \mathrm{~nm}) / \mathrm{Ir}(\mathrm{ppz})_{3}(10$ $\mathrm{nm}) / \mathrm{host}: \operatorname{Ir}(\mathrm{MDQ})_{2}(\mathrm{acac}) \quad(6 \mathrm{wt} \quad \%) \quad(10 \mathrm{~nm}) /$ Bphen $\quad(40 \quad \mathrm{~nm}) / \mathrm{LiF} \quad\left(\begin{array}{llll}1 & \mathrm{~nm}\end{array}\right) / \mathrm{Al} \quad(100 \mathrm{~nm})$ (red-PhOLEDs), (Devices 1-3: host $=$ SFX-bPy, SFX-DbPy and SFX-TbPy, respectively). $\mathrm{MoO}_{x}$ and $\mathrm{LiF}$ were used as hole- and electron-injecting layers, and $m$-MTDATA and BPhen were used as the hole- and electron-transporting layers (HTL and ETL), respectively. $\operatorname{Ir}(\mathrm{ppz})_{3}$ was employed as the hole-transporting and electron-blocking material (see the device configuration and the molecular structures in Scheme 2).

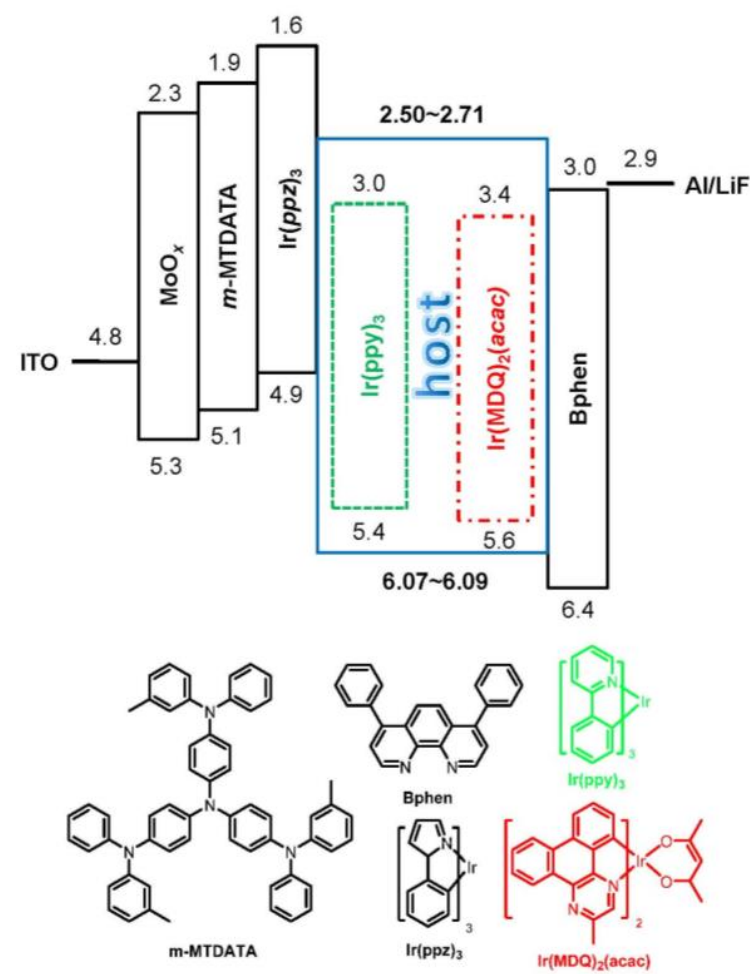

Scheme 2. Configuration and energy-level diagram of PHOLEDs based on SFX-bPy, SFX-DbPy and SFX-TbPy hosts. 
The electroluminescent spectra, luminance-voltage-current density $(L-V-J)$ and external quantum efficiency (EQE) of the green devices are shown in Fig.3 and the detailed performance is summarized in Table 3. All of the green devices exhibited the same emission spectra peaking at $514 \mathrm{~nm}$, which was attributed to $\operatorname{Ir}(\mathrm{ppy})_{3}$ by full energy transfer from hosts to guest (Fig. 3a). The devices exhibited low turn-on voltages in the range of 2.60-2.70 V at a brightness of $1 \mathrm{~cd} \mathrm{~m}^{-2}$ (determined from Fig. 3b). At the same luminance, the device G1 always possesses the lowest operating voltages among these green devices (Fig. 3b). It is noticed that the operating voltage of $\mathrm{G} 1$ is about $3.82 \mathrm{~V}$ at the luminance of $1000 \mathrm{~cd} \mathrm{~m}^{-2}$, which is mainly derived from the appropriate host-dopant triplet energy gap between SFX-bPy and Ir(ppy) $)_{3}\left(T_{1}: 2.55 \mathrm{eV}\right.$ for SFX-bPy; about 2.4 $\mathrm{eV}$ for $\operatorname{Ir}(\mathrm{ppy})_{3}$ ). Simultaneously, the device G1 has the highest device efficiencies among the green devices, with the maximum current efficiency (CE) of $23.6 \mathrm{~cd} \mathrm{~A}^{-1}$, power efficiency (PE) of $23.4 \mathrm{~lm} \mathrm{~W}^{-1}$ and external quantum efficiency (EQE) of $6.3 \%$ (Table 3). This is mainly ascribed to more harmonious carriers-transport ability of SFX-bPy besides the advantage of its higher $T_{1}$. The devices G2 and G3 show higher operating voltages and inferior device performances, and the device G3 has the worst performance among these green devices (Table 3). Owing to the almost same $T_{1}$ energy level for both SFX-DbPy and SFX-TbPy, triplet energy transfer from the hosts to the phosphors can be considered to be approximately identical for G2 and G3. According to the results of single-carrier-transport devices (Fig. 2), the hole-transporting ability of SFX-DbPy and SFX-TbPy is very close, however, electron-transporting ability between the two is significantly different. The carrier transport in SFX-TbPy-based device is less balanced than that in SFX-DbPy-based device, which might cause higher exciton concentration in the partial area of EML and less restrained TTA in the device G3. Thus, the performance of device G3 is the worst. Therefore, the best performance of SFX-bPy-based device (G1) can be attributed to the following advantages, i) high $T_{1} v s$. the green phosphor; ii) more balanced carrier-transporting ability; iii) the more rigid and asymmetrical characteristics of the molecular structure [54,55]. However, the $T_{1}$ is still considerably lower than these of other D-A type spiro host molecules such as $\mathrm{SPA}^{-\mathrm{TXO}_{2}}$ [18] and CSC [19] (Chart 1). The low $T_{1}$ is presumably a result of extended conjugation between the

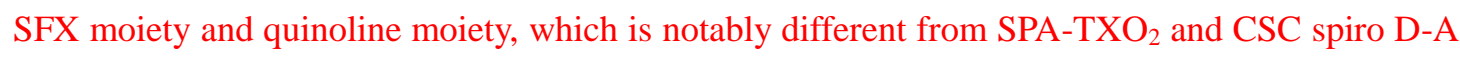
systems where the donor unit and the acceptor unit are not directly conjugated. This low $T_{1}$, together with different device structures, may contribute to the relatively inferior efficiency of these SFX-quinoline host-based devices. 

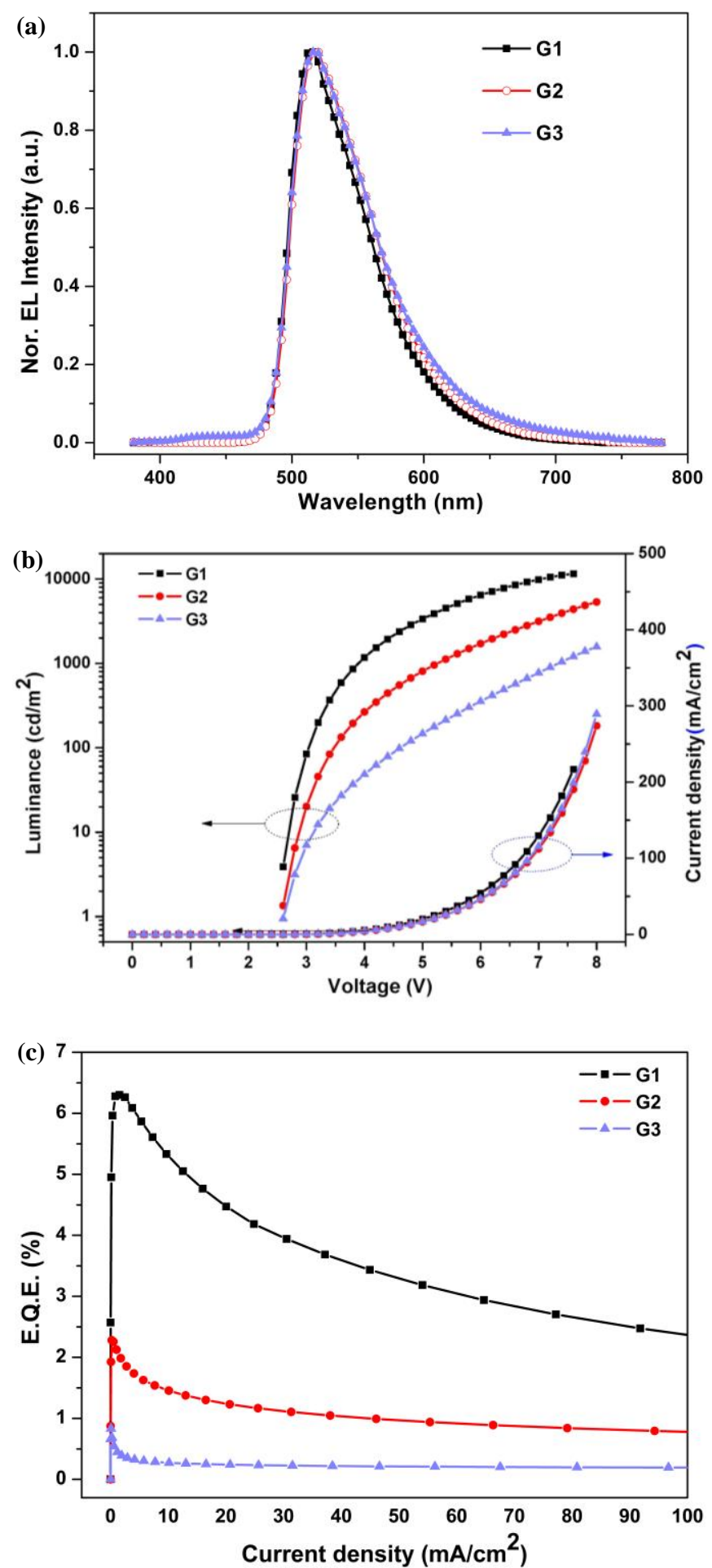

Fig.3. Device characteristics of the green PhOLEDs: (a) the EL spectra (7 V), (b) current density-luminance-voltage, (c) external quantum efficiency.

The device performance of the red PhOLEDs hosted by SFX-bPy, SFX-DbPy and SFX-TbPy were also measured. As shown in Fig. 4. The EL spectra did not show any other residual emission peaks with constant CIE coordination at $(0.61,0.39)$ (Table 3$)$. However, the trend is completely different between the red device performance and the green device hosted by the same host. The device R2 hosted by SFX-DbPy possesses the best performance among these red devices, with the $\mathrm{CE}$ of $15.8 \mathrm{~cd} \mathrm{~A}^{-1}$, PE of $16.0 \mathrm{~lm} \mathrm{~W}^{-1}$ and EQE of $9.1 \%$ (Fig.4b, Table 3). In addition, all of the red 
devices have similar and better efficiencies, which is also different from the green devices that the device G1 is only one with good performance. In contrast, the performance of device R1 hosted by SFX-bPy is the worst among these red devices, although the compound SFX-bPy possesses higher $T_{1}$. However, the lowered LUMOs of SFX-DbPy and SFX-TbPy are conducive to the injecting/transporting of carriers in these red PhOLED devices, so devices R2 and R3 show higher current density than device R1 (Fig.4b). Furthermore, red phosphors commonly suffer from much worse triplet-involved quenching effects due to their high polarities, narrow energy gaps, and longer lifetimes, which led to a higher demand for polarized host materials [56]. To a certain extent, it is a benefit that red phosphorescent host materials possess highly polarized and small conjugated systems [57,58]. According to the results of the DFT simulation (Table 2), the FMOs of SFX-DbPy and SFX-TbPy are more separate than the FMO of SFX-bPy. Therefore, the compounds SFX-DbPy and SFX-TbPy are more polarizable, and thus make up for the performance enhancement in the corresponding devices. Furthermore, the compound SFX-TbPy has a higher conjugation degree at the xanthene moiety compared with SFX-DbPy, so the performance of device R3 falls slightly compared with the device R2.

(a)
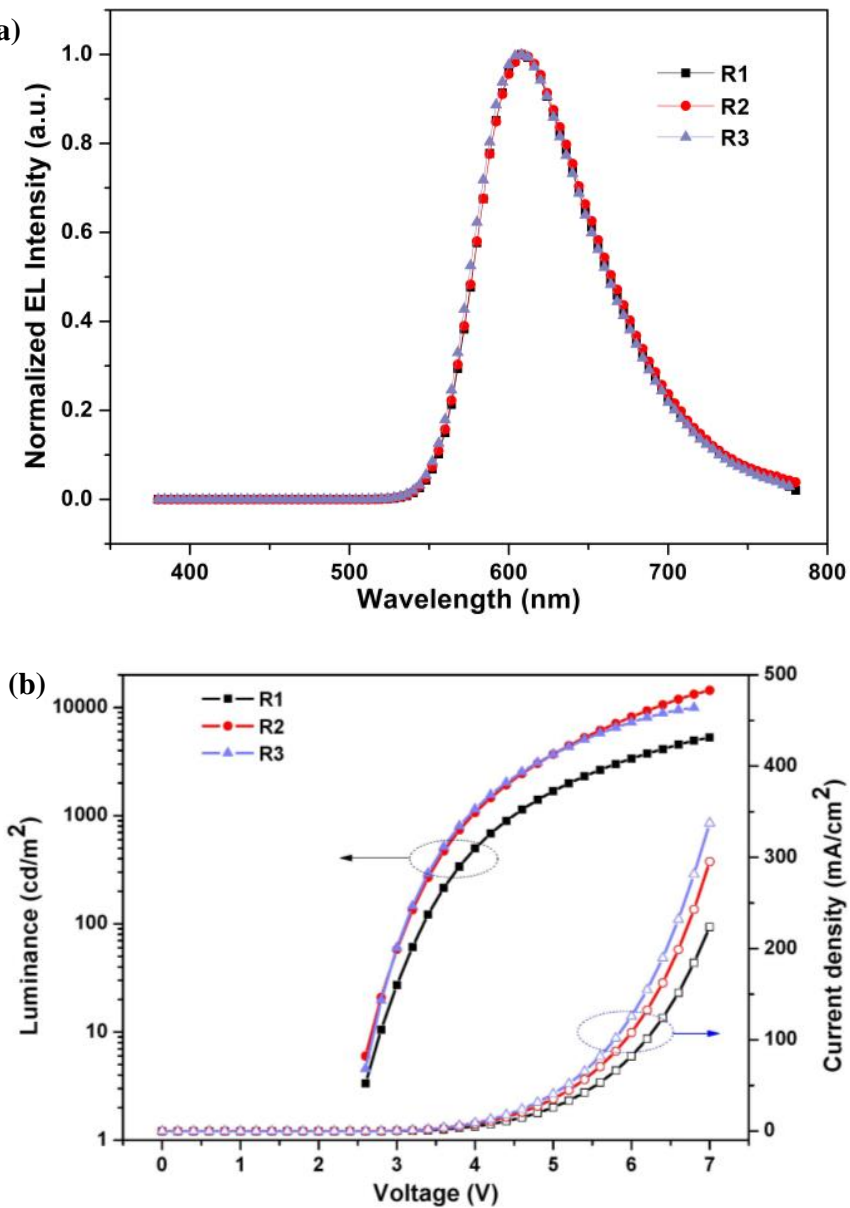


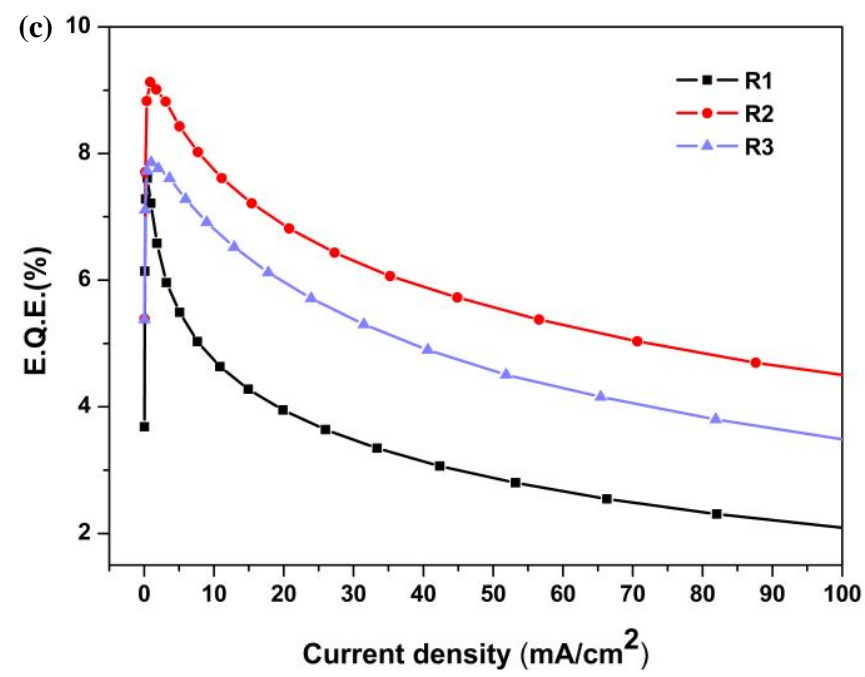

Fig. 4. Device characteristics of the red PhOLEDs: (a) the EL spectra (7 V), (b) current density-luminance-voltage, (c) external quantum efficiency.

Table 3. Performance of green-emitting and red-emitting devices based on SFX-bPy, SFX-DbPy and SFX-TbPy.

\begin{tabular}{ccccccc}
\hline \multirow{2}{*}{ Device } & \multirow{2}{*}{$\mathrm{V}^{a}$} & $\mathrm{~L}_{\max }{ }^{b}$ & \multicolumn{3}{c}{ Maximum efficiencies } & \multirow{2}{*}{ CIE $^{c}$} \\
\cline { 4 - 6 } & & & C.E. $\left(\mathrm{cd} \mathrm{A}^{-1}\right)$ & P.E. $\left(\mathrm{lm} \mathrm{W}^{-1}\right)$ & E.Q.E (\%) & \\
\hline G1 & 3.82 & 11570 & 23.6 & 23.4 & 6.3 & $0.63,0.29$ \\
$\mathrm{G} 2$ & 5.22 & 5347 & 8.6 & 9.0 & 2.3 & $0.62,0.30$ \\
$\mathrm{G} 3$ & 7.28 & 1575 & 3.0 & 3.3 & 0.7 & $0.61,0.31$ \\
R1 & 3.91 & 5282 & 13.6 & 13.3 & 7.6 & $0.61,0.39$ \\
R2 & 3.95 & 14400 & 15.8 & 16.0 & 9.1 & $0.61,0.39$ \\
R3 & 4.48 & 9946 & 14.6 & 15.0 & 7.9 & $0.61,0.39$ \\
\hline
\end{tabular}

${ }^{a}$ Operating voltage at $1000 \mathrm{~cd} \mathrm{~m}^{-2}$.

${ }^{b}$ Maximum Luminescence $\left(\mathrm{cd} \mathrm{m}^{-2}\right)$.

${ }^{c}$ Commission International de I'Eclairage coordinates $(\mathrm{x}, \mathrm{y})$.

\section{Conclusions}

In summary, three SFX derivatives bearing up to three quinolyl groups were designed and synthesized as host materials for PhOLEDs. The substitution effect of quinoline on SFX was investigated by optophysical and electrochemical studies. It was found that when quinoline was sequentially introduced onto 2', 2 and 7' positions of SFX, the HOMO energy levels remained similar while the LUMO was increasingly stabilized. All of these molecules exhibited bipolar characteristics as host materials for green and red PhOLED devices. For green devices, the one hosted by SFX-bPy showed the highest performance with a driving voltage of $3.8 \mathrm{~V}$ at $1000 \mathrm{~cd}$ $\mathrm{m}^{-2}$, CE of $23.6 \mathrm{~cd} \mathrm{~A}^{-1}$ and EQE of $6.3 \%$. The better performance could be attributed to the high $T_{1}$ and balanced carriers-transporting ability of SFX-bPy. On the other hand, the red devices displayed better device characteristics than the corresponding green ones, in which the best with a driving voltage of $3.95 \mathrm{~V}$ at $1000 \mathrm{~cd} \mathrm{~m}^{-2}, \mathrm{CE}$ of $15.8 \mathrm{~cd} \mathrm{~A}^{-1}$ and $\mathrm{EQE}$ of $9.1 \%$. It indicates that matching $T_{1}$ and appropriate separation of FMOs can further enhance the performance of hosts. This work sheds light on the impact of structural modification of SFX by extended conjugation on 
fluorene and xanthene moieties, which provides a more informed search for SFX-based bipolar hosts for high performance PhOLEDs.

\section{Acknowledgements}

We express our sincere gratitude to the Doctoral Research Foundation of Liaoning Province (20131091), National Natural Scince Foundation of China (grant no. 61405170) and Students Sustentation Fund of Xinyang Normal University (No. 2014-DXS-136). Y. L. acknowledges the support from the Molecular Foundry, a user facility supported through the Office of Science, Office of Basic Energy Sciences, of the U.S. Department of Energy, under Contract No. DE-AC02-05CH11231.

\section{Appendix A. Supplementary data}

Supplementary data associated with this article can be found, in the online version, at http://dx.doi.org/10.1016/j.orgel.2016.??????.

\section{References}

[1] M.A. Baldo, D.F. O'Brien, Y. Yu, A. Shoustikov, S. Sibley, M.E. Thompson, S.R. Forrest, Nature 395 (1998) 151.

[2] B. D'Andrade, Nat. Photonics 1 (2007) 33.

[3] C.C. Lai, M.J. Huang, H.H. Chou, C.-Y. Liao, P. Rajamalli, C.-H. Cheng, Adv. Funct. Mater. 25 (2015) 5548.

[4] Y. Tao, C. Yang, J. Qin, Chem. Soc. Rev. 40 (2011) 2943.

[5] H. Liu, Q. Bai, L. Yao, D. Hu, X. Tang, F. Shen, H. Zhang, Y. Gao, P. Lu, B. Yang, Y. Ma, Adv. Funct. Mater. 24 (2014) 5881.

[6] Y. Tao, Q. Wang, C. Yang, Q. Wang, Z. Zhang, T. Zou, J. Qin, D. Ma, Angew. Chem. 120 (2008) 8224.

[7] C. Fan, Y. Chen, Z. Jiang, C. Yang, C. Zhong, J. Qin, D. Ma, J. Mater. Chem. 20 (2010) 3232.

[8] E. Mondal, W.Y. Hung, Y.H. Chen, M.H. Cheng, K.T. Wong, Chem. Eur. J. 19 (2013) 10563.

[9] A.L. Fisher, K.E. Linton, K.T. Kamtekar, C. Pearson, M.R. Bryce, M.C. Petty, Chem. Mater. 23 (2011) 1640.

[10] M. Romain, D. Tondelier, J.-C. Vanel, B. Geffroy, O. Jeannin, J. Rault-Berthelot, R. Métivier, C. Poriel, Angew. Chem. Int. Ed. 52 (2013) 14147.

[11] S. Thiery, D. Tondelier, B. Geffroy, E. Jacques, M. Robin, R. Métivier, O. Jeannin, J. Rault-Berthelot, C. Poriel, Org. Lett. 17 (2015) 4682.

[12] Y. Shirota, M. Kinoshita, T. Noda, K. Okumoto, T. Ohara, J. Am. Chem. Soc. 122 (2000) 11021.

[13] C.-H. Chen, L.-C. Hsu, P. Rajamalli, Y.-W. Chang, F.-I. Wu, C.-Y. Liao, M.-J. Chiu, P.-Y. Chou, M.-J. Huang, L.-K.Chu, C.-H. Cheng, J. Mater. Chem. C 2 (2014) 6183.

[14] G. Méhes, H. Nomura, Q. Zhang, T. Nakagawa, C. Adachi, Angew. Chem. Int. Ed. 51 (2012) 11311.

[15] M. Romain, D. Tondelier, O. Jeannin, B. Geffroy, J. Rault-Berthelot, C. Poriel, J. Mater. Chem. C 3 (2015) 9701.

[16] M. Romain, D. Tondelier, B. Geffroy, O. Jeannin, E. Jacques, J. Rault-Berthelot, C. Poriel, Chem. Eur. J. 21 (2015) 9426.

[17] C. Fan, Y. Chen, Z. Liu, Z. Jiang, C. Zhong, D. Ma, J. Qina, Chuluo Yang, J. Mater. Chem. C 
1 (2013) 463.

[18] M. Romain, D. Tondelier, B. Geffroy, A. Shirinskaya, O. Jeannin, J. Rault-Berthelot, C. Poriel, Chem. Commun. 51 (2015) 1313.

[19] H.-F. Chen, T.-C. Wang, W.-Y. Hung, H.-C. Chiu, C. Yun, K.-T. Wong, J. Mater. Chem. 22 (2012) 9658.

[20] C. Fan, Y. Chen, P. Gan, C. Yang, C. Zhong, J. Qin, D. Ma, Org. Lett. 12 (2010) 5648.

[21] Y. Tao, L. Ao, Q. Wang, C. Zhong, C. Yang, J. Qin, D. Ma, Chem. Asian. J. 5 (2010) 278.

[22] T. P. Saragi, T. Spehr, A. Siebert, T. Fuhrmann-Lieker, Salbeck, J. Chem. Rev. 107 (2007) 1011.

[23] S.Y. Ku, W.Y. Hung, C.W. Chen, S.W. Yang, E. Mondal, Y. Chi, K.T. Wong, Chem. Asian. J. 7 (2012) 133.

[24] L. Wang, B. Pan, L. Zhu, B. Wang, Y. Wang, Y. Liu, J. Jin, J. Chen, D. Ma, Dyes. Pigm. 114 (2015) 222.

[25] S. Thiery, D. Tondelier C. Declairieux, B. Geffroy, O. Jeannin, R. Métivier, J. Rault-Berthelot, C. Poriel, J. Phys. Chem. C 119 (2015) 5790.

[26] L.-S. Cui , Y.-M. Xie , Y.-K. Wang, C. Zhong, Y.-L. Deng , X.-Y. Liu , Z.-Q. Jiang, L.-S. Liao, Adv. Mater. 27 (2015) 4213.

[27] L. H. Xie, F. Liu, C. Tang, X. Y. Hou, Y. R. Hua, Q. L. Fan, W. Huang, Org. Lett. 8 (2006) 2787.

[28] L. H. Xie, J. Liang, J. Song, C.R. Yin, W. Huang, Curr. Org. Chem. 14 (2010) 2169.

[29] M. Maciejczyk, A. Ivaturi, N. Robertson, J. Mater. Chem. A 4 (2016) 4855.

[30] B. Xu, D. Bi, Y. Hua, P. Liu, M. Cheng, M. Grätzel, L. Kloo, A. Hagfeldt, L. Sun, Ener. Envir. Sci. 9 (2016) 873.

[31] S. Zhang, Y. Li, T. Ma, J. Zhao, X. Xu, F. Yang, X.Y. Xiang, Poly. Chem. 1 (2010) 485.

[32] D. Lin, M. Sun, Y. Wei, L. Xie, X. Zhang, W. Huang, Chin. Sci. Bull. 60 (2015) 1237.

[33] J.F. Gu, G.H. Xie, L. Zhang, S.F. Chen, Z.Q. Lin, Z.S. Zhang, J.F. Zhao, L.H. Xie, C. Tang, Y. Zhao, S.Y. Liu, W. Huang, J. Phys. Chem. Lett. 1 (2010) 2849.

[34] M.L. Sun, W.S. Zhu, Z.S. Zhang, C.J. Ou, L.H. Xie, Y. Yang, Y. Qian, Y. Zhao, W. Huang, J. Mater. Chem. C 3 (2015) 94.

[35] N. Cocherel, C. Poriel, L. Vignau, J.F. Bergamini, J. Rault-Berthelot, Org. Lett. 12 (2010) 452.

[36] C. Poriel, N. Cocherel, J. Rault-Berthelot, L. Vignau, O. Jeannin, Chem. Eur. J. 17 (2011) 12631

[37] J. Zhao, G.H. Xie, C.R. Yin, L.H. Xie, C.M. Han, R.F. Chen, H. Xu, M.D. Yi, Z.P. Deng, S.F. Chen, Y. Zhao, S.Y. Liu, W. Huang, Chem. Mater. 23 (2011) 5331.

[38] Q. Zhang, D. Fang, H. Jiang, X. Zhang, H. Zhang, Org. Elect. 27 (2015) 173.

[39] M. Sun, Y. Guan, B Liu, S. Chen, Y. Zhang, H. Cao, L. Xie, Y. Qian, W. Huang, Gen. Chem. 1 (2015) 3 .

[40] Y. Qian, Y. Ni, S. Yue, W. Li, S. Chen, Z. Zhang, L. Xie, M. Sun, Y. Zhao, W. Huang, RSC Adv. 5 (2015) 29828.

[41] Y. Qian, G. Xie, S. Chen, Z. Liu, Y. Ni, X. Zhou, L. Xie, J. Liang, Y. Zhao, M. Yi, Y. Zhao, W. Wei, W. Huang, Org. Elect. 13 (2012) 2741.

[42] M. L. Sun, S. Z. Yue, J. R. Lin, C. J. Ou, Y. Qian, Y. Zhang, Y. Li, Q. Wei, Y. Zhao, L. H. Xie, W. Huang, Syn. Met. 195 (2014) 321. 
[43] J. Li, D. Ding, Y. Tao, Y. Wei, R. Chen, L. Xie, W. Huang, H. Xu, Adv. Mater. 28 (2016) 3122.

[44] M. Pietraszkiewicz, M. Maciejczyk, I. D. W. Samuel, S. Zhang, J. Mater. Chem. C 1 (2013), 8028.

[45] X.H. Zhao, G.H. Xie, Z.D. Liu, W.J. Li, M.D. Yi, L.H. Xie, C.P. Hu, R. Zhu, Q. Zhao, J.F. Zhao, Y. Qian, W. Huang, Chem. Commun. 48 (2012) 3854.

[46] Z. Chu, D. Wang, C. Zhang, F. Wang, H. Wu, Z. Lv, S. Hou, X. Fan, D. Zou, Syn. Met. 162 (2012) 614.

[47] A. K. Agrawal, S. A. Jenekhe, Chem. Mater. 4 (1992) 95.

[48] A. K. Agrawal, S. A. Jenekhe, Macromolecules, 26 (1993) 895.

[49] C.H. Chen, L.C. Hsu, P. Rajamalli, Y.W. Chang, F.I. Wu, C.Y. Liao, M.J. Chiu, P.Y. Chou, M.J. Huang, L.K. Chu, C.H. Cheng, J. Mater. Chem. C 2 (2014) 6183.

[50] M.J. Frisch, G.W. Trucks, H.B. Schlegel, G.E. Scuseria, M.A. Robb, J.R. Cheeseman, G. Scalmani, V. Barone, B. Mennucci, G.A. Petersson, et al., Gaussian 09, Revision A.1, Gaussian, Inc., Wallingford CT, 2009.

[51] L. Zhang, N.S. Colella, B.P. Cherniawski, S.C. Mannsfeld, A.L. Briseno, ACS Appl. Mater. Inter. 6 (2014) 5327.

[52] H. E. Katz, Z. Bao, S. L. Gilat, Acc. Chem. Res. 34 (2001) 359.

[53] S.J. Yeh, M.F. Wu, C.T. Chen, Y.H. Song, Y. Chi, M.H. Ho, S.F. Hsu, C.H. Chen, Adv. Mater. 17 (2005) 285

[54] Q. Li, L.S. Cui, C. Jiang, Z.Q. Zhong, L.S Liao, Org. Lett. 16 (2014) 1622.

[55] M.J. Kim, C.W. Lee, M.S. Gong, Dyes Pigm. 105 (2014) 202.

[56] D.H. Kim, N.S. Cho, H.Y. Oh, J.H. Yang, W.S. Jeon, J.S. Park, M.C. Suh, J.H. Kwon, Adv. Mater. 23 (2011) 2721.

[57] K. Wang, F. Zhao, C. Wang, S. Chen, D. Chen, H. Zhang, Y. Liu, D. Ma, Y. Wang, Adv. Funct. Mater. 23 (2013) 2672.

[58] C. Fan, P. Sun, T.H. Su, C.H. Cheng, Adv. Mater. 23 (2011) 2981. 